\title{
XIX. On the liquefaction of gases
}

\section{Prof. Charles Olszewski}

To cite this article: Prof. Charles Olszewski (1895) XIX. On the liquefaction of gases , Philosophical Magazine, 39:237, 188-212, DOI: 10.1080/14786449508620703

To link to this article: http://dx.doi.org/10.1080/14786449508620703

\section{Published online: 08 May 2009.}

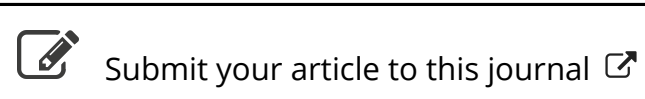

\footnotetext{
Џll Article views: 13
}

Q View related articles $\asymp$

4 Citing articles: 4 View citing articles 진 


\section{On the Liquefaction of Gases. By Prof. Dr. Charles Olszewski*.}

$\mathbf{M}^{\mathrm{Y}}$ researches concerning the liquefaction of gases, with which I have been occupied ever since the year 1883, have been published in various scientitic periodicals in the Polish, French, and German languages, viz., in the publications of the Academy of Sciences of Cracow (in Polish), in the Bulletin International of the sume Academy (in French and German), in the Annals of the Academy of Sciences of Vienna, and in Wiedemann's Annalen der Physik und Chemie and in his Beiblätter, as well as in the Comptes Rendus. Though I suppose that my labours are sufficiently known to the scientific world, yet there are motives which lead me to ask the Editors of the Philosophical Magazine to insert the following summary of the more important results of my experiments.

Firstly, because my researches appeared irregularly in different scientific papers, as they proceeded; such as wished to become acquainted with them being obliged to look them up in all the papers I have mentioned. Secondly, because of the experiments and public lectures of Prof. James Dewar, concerning the liquefaction of large quantities of oxygen and air. In several cases Prof. Dewar merely repeated my experiments : for instance, as regards the absorption spectrum and the colour of liquefied oxygen. In these cases he confirmed the observations I have made, and mentioned the results of my work in the manner usually received in the scientific world. But in his last experiments and lectures respecting the liquefaction of considerable quantities of oxygen and air and their employment as cooling agents, Prof. Dewar has thought fit not to make any mention of my labours in the same field, which had been published several years before Prof. Dewar went over them again. In the number for June 1890 of the Bulletin International de l'Académie de Cracovie, I have described an apparatus serving to liquefy a greater quantity of oxygen or air in a steel cylinder, from which it can be poured out into an open glass vessel, and used as a frigorific agent. It is entitled " $\mathrm{K}$. Olszewski. Transvasement de l'oxygène liquide ;" and a brief report on the subject is contained in the Beiblätter of Wiedemann, vol. xv. p. 29, under the title "K. Olszewski. Ueber das Giessen des flüssigen Sauerstoffs." That my labours should have thus been passed

* Communicated by the Author, 
over in silence is all the more astonishing, because as soon as the above-mentioned Bulletin was printed I sent a proof of it to Prof. Dewar ; I also forwarded him proofs of my other researches, knowing that they interest him.

The apparatus I constructed and described works very well and can be used without danger, so that in October of the same year (1890) I was enabled to obtain 100 cub. centim. of liquid oxygen in the presence of an audience consisting of over 100 students. In the following year, during the Congress of Polish naturalists and physicians in Cracow (July 1891) I obtained 200 cub. centim. of liquid oxygen in the presence of a good many physicists, and showed its peculiar properties; as, e.g., its bluish colour and its absorption spectrum. Subsequently, without having altered my apparatus in any way, I got about 200 cub. centim. of liquid air and used it as a frigorific agent in order to liquefy hydrogen. The construction of my apparatus is very simple, and it can easily be enlarged by using a steel cylinder of the capacity of 300,400 , 500 , or more cubic centimetres. The only reason that I have never hitherto employed a steel cylinder of greater capacity than 200 cub. centim., is the circumstance that the quantity of oxygen or air which can be liquefied in this cylinder was quite sufficient for my experiments.

After these remarks, I shall now give a summary of the more important results of $\mathrm{my}$ former labours concerning the liquefaction and solidification of gases, and then describe the apparatus I constructed, which serves to obtain great quantities of liquefied oxygen and air ; also stating my experiments made in order to liquefy hydrogen, by using large quantities of liquid oxygen or liquid air as frigorific agents.

Summary of the Results of my former Experiments.

In 1883, and for several years following, I liquefied the gases in a strong glass tube, about 30 centim. in length, 14-18 millim. in diameter within, with walls from 3 to 4 millim. thick. Oxygen, nitrogen, atmospheric air, carbon monoxide, nitric oxide, and methane, submitted to the influence of cold in the tube by means of liquid ethylene, boiling in vacuo at a temperature of $-150^{\circ} \mathrm{C}$., were easily liquefied under a pressure not beyond $50 \mathrm{~atm}$. As my experiments proceeded, I published their results in the periodicals I have montioned; and a detailed description of the apparatus I used in my experiments is contained in Wiedemann's Annalen der Physik und Chemie, 1887 , vol. xxxi. p. 58 , under the title " $\mathrm{K}$. Olszewski. Ueber die Dichte des flüssigen Methans sowie des 
verflüssigten Sauerstoffs und Stickstoffs." In this apparatus I liquefied all the gases spoken of, in quantities varying from a few to a good many cubic centimetres of liquid, and determined their critical temperatures and pressures, as well as their boiling-points under ntmospheric pressure. I succeeded in solidifying four of these gases, viz., nitrogen (6), carbon monoxide (6), nitric oxide (7), and marsh-gas (7), by lowering the pressure to several millimetres of mercury, and determined their freezing-points and the corresponding pressures of solidification. I also showed that liquid oxygen and air boiling in vacuo at a pressure of 4 millimetres of mercury do not freeze though their temperatures are lowered to below $-211^{\circ}$ and $-220^{\circ} \mathrm{C}$. By diminishing the pressure of solid nitrogen to 4 millimetres of mercury, I obtained a temperature reaching $-225^{\circ} \mathrm{C}$., the lowest that has ever been obtained and measured (6).

With the same apparatus I also made a series of experiments with reference to the liquefaction of hydrogen, submitting it to a pressure reaching $180 \mathrm{~atm}$., and at the same time cooling it down to $-211^{\circ}$ and even $-220^{\circ} \mathrm{C}$., by means of liquid ethylene and liquid air boiling in vacuo (2). I also showed that the critical temperature of hydrogen is below $-220^{\circ} \mathrm{C}$. In the same apparatus which served for the liquefaction of hydrogen I liquefied a mixture of two volumes hydrogen and one volume oxygen, and thus obtained a liquid which was in thin layers colourless and transparent (8). I likewise determined the specific gravity of oxygen, nitrogen, and methane at the boiling-points of these gases (15). The same apparatus was also of use for examination of the absorption spectrum of liquid oxygen and air, and showed that liquid oxygen in layers not thicker than 7 millim. absorbs light very strongly; also that it gives, among others, two strong absorption bunds, corresponding in position to two absorptions of the solar rays, which are due to the oxygen in the air (13). Using liquid oxygen as a cooling agent, $\bar{I}$ obtained pure ozone in the shape of a dark-blue liquid, easily and violently exploding, and of which I determined the boiling-point (12).

Besides the above-mentioned gases, I have examined another series with regard to their behaviour at low temperatures, especially those which had not yet been examined in this respect, or which had been examined without success. I first solidified the following gases and determined their meltingpoints : chlorine (10), hydrochloric acid (10), hydrofluoric acid (11), phosphine (11), arsine (10), stibine (11), ethylene (12), [silicon tetrafluoride * (10)]. Moreover, I determined

* Does not melt, but evaporates in solid state. 
the boiling-points of ethane (17), propane (17), and hydrogen selenide (19), as well as their critical temperatures and pressures. The following liquids were solidified for the first time by me :-methyl (14), ethyl (14), amyl alcohol (10), ethyl ether (10), carbon bisulphide (14), and phosphorous chloride $\left(\mathrm{PCl}_{3}\right)(14)$.

In order to measure very low temperatures, I used exclusively a hydrogen thermometer: the bulb was plunged in the liquefied gas itself; only exceptionally a few not very low temperatures were measured with the carkon-bisulphide thermometer. Wishing to ascertain how far gas-thermometers may be used to measure very low temperatures, I compared thermometers filled with different gases, and especially the hydrogen thermometer with the nitrogen, oxygen, and nitric-oxide thermometers, immersing them in liquid ethylene, gradually cooled to $-151^{\circ} \mathrm{C}$. It was proved by this that the three last-mentioned thermometer's indicated temperatures not very different from those indicated by the hydrogen thermometer, even at temperatures much lower than the critical temperatures of the corresponding gases.

This experiment proved at the same time that nitric oxide does not change its molecular weight, corresponding to the formula NO, even at a temperature so low as $-147^{\circ} \mathrm{C}$. Profs. Victor Meyer and Daccomo, disregarding the results of my investigations, performed a similar experiment (Liebig's Ann. $d$. Chem. ccxl. p. 326), but they cooled the nitric oxide with solid earbon dioxide and ether down to $-70^{\circ} \mathrm{C}$. only.

As, according to my experiments on the liquefaction of hydrogen, its critical temperature lies below $-220^{\circ} \mathrm{C}$., it may be admitted that its coefficient of expansion does not, even at $-220^{\circ} \mathrm{C}$., differ much from the coefficient of gases at ordinary temperatures, and that hydrogen is the only body which can be used in a thermometer for measuring very low temperatures. The determinations of the temperatures by measuring the quantity of heat taken away from a given body, a silver ball for instance, is not precise; for, as Zakrzewski* showed, the specific heat of silver changes in the interval of $0^{\circ}$ to $-100^{\circ} \mathrm{C}$. by about 3 per cent.; so that the temperature which is thus determined must differ from the true one to some not inconsiderable extent. Thermoelectric thermometers, or thermometers based upon the variation of the electric conductivity of metals at low temperatures, can be used only in the limits between which they have been compared with the hydrogen thermometer; every extrapolation may lead to great mistakes. An excellent thermo-

* Bullet. Intern. of the Acad. of Cracow, A pril 1891, p. 146. 
meter, based on the alteration of the electric conductivity of a thin iron wire, has been constructed by Prof. Witkowski *, my fellow-worker on the optic properties of liquid oxygen.

\section{Liquefaction of Large Quantities of Oxygen and Air.}

Description of the apparatus given in the Bulletin International de $l$ 'Académie des Sciences de Cracovie, June 1890, under the title, "K. Olszewski, Transvasement de l'Oxygène liquide."]

Though I have simplified and improved my former apparatus for liquefying gases to such a degree that $I$ have been able to show the liquefaction of oxygen to a numerous anditory during the lecture, yet it leaves much to be desired as regards the practical application of liquefied gases as cooling agents.

By means of my former apparatus I was able to obtain only small quantities of liquefied gases ; a greater diameter could not be given to the glass tubes used for the purpose, because they would not resist the high pressure which is necessary for liquefaction. Besides this, the use of glass tubes exposed to high pressures is always attended with some danger : it often happens that tubes tested for $60 \mathrm{~atm}$. sometimes burst during the experiment at 40 atm., or even at a lower pressure.

I proved long ago (6) that liquid oxygen is the best cooling agent; for it easily gives the temperature of $-211^{c} .5 \mathrm{C}$. if the pressure is lowered to 9 millim. of mercury, and it does not freeze even at the pressure of 4 millim.

To obtain considerably larger quantities of liquid oxygen for the purpose of applying it as a frigorific agent, it was necessary, instead of brittle glass, to use a substance endowed with more resisting-power, even though not transparent, and to find means to pour the liquid oxygen into a glass vessel. My new apparatus excludes the inconveniences of the former one, and renders it possible to preserve the liquid oxygen a longer time under the ordinary atmospheric pressure.

A flask of wrought iron, 5 litres in capacity (such as is used to hold liquid carbon dioxide), containing oxygen under a pressure of $80 \mathrm{~atm}$., is joined by a narrow copper tube to the upper end of a steel cylinder tested at a pressure of $200 \mathrm{~atm}$. 'This cylinder, having a capacity of 30-100 cub. centim., according to the quantity of oxygen which we wish to liquefy at a time, is immersed in liquid ethylene, of which the temperature may easily be lowered to $-140^{\circ} \mathrm{C}$. by means of an

* Bull. Intern. of the Acad. of Cracow, May 1891, p. 188. 
air-pump. The lower end of the cylinder is joined by a narrow copper tube to a little stopcock, through which the oxygen, liquefied in the cylinder, can be poured down into an open glass vessel kept cool by the surrounding air. Owing to this isolation, liquid oxygen contained in the open vessel evaporates but very slowly; and when after some time its quantity has considerably decreased, a new portion which has been liquefied in the meantime can be led down into the vessel by turning the cock. This may be continued until the store of ethylene serving to cool the cylinder and the amount of oxygen in the iron flask are exhausted. $240 \mathrm{~g}$. of liquid ethylene suffice to keep the oxygen liquid at the atmospheric pressure for half an hour.

By connecting the glass vessel which contains the liquid oxygen with a good air-pump, its temperature can easily be lowered to $-211^{\circ} \mathrm{C}$. Thus was solved the problem of liquefying considerable quantities of oxygen without the slightest danger. This decides me to resume my former experiments concerning the liquefaction of hydrogen ; and I hope thereby to obtain more successful results.

To this description, which I have given in a literal translation from the above-mentioned Bulletin International, I subjoin a diagram (fig. 1) representing a section of my apparatus, which I shall shortly explain. But I must remark that in the same year (1890), when proceeding to my experiments on the liquefaction of hydrogen, I doubled the dimensions of the apparatus without changing anything in its construction. The dimensions that I shall afterwards give refer to the enlarged apparatus.

The steel cylinder $a$, of a capacity of $200 \mathrm{cub}$. centim., has its upper end connected by means of a thin copper tube with a metallic manometer $b$, and an iron bottle $c 10$ litres in capacity, containing dry oxygen or air under a pressure of $100 \mathrm{~atm}$., the lower aperture of the cylinder $a$ being connected by a very thin copper tube with the little cock $d$, which serves to let out the liquefied oxygen or air. The cylinder $a$ is placed in a glass vessel $m$ with double or treble walls, which serves to receive the liquid ethylene, of which the iron flask $f$ is the reservoir. This flask (3 litres in eapacity) is shaped like a siphon, and contains about 1 kilog. of liquid ethylene. The ethylene, liquefied and cooled in the flask $f$ by means of ice and salt, passes, after the cock is turned, into the condenser $g$ filled with a mixture of ether and solid carbon dioxide. To lower the temperature of this mixture $-78^{\circ} \mathrm{C}$.)

Phil. Mag. S. 5. Vol. 39. No. 237. Feb. 1895. 
to $-100^{\circ} \mathrm{C}$, the tube $n$ is connected with a smaller doubleaction pump which at every movement of the piston draws

Fig I.
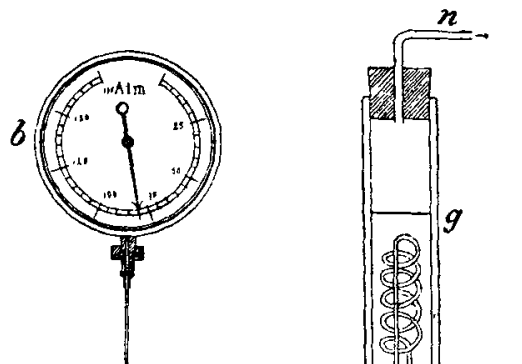

$c$
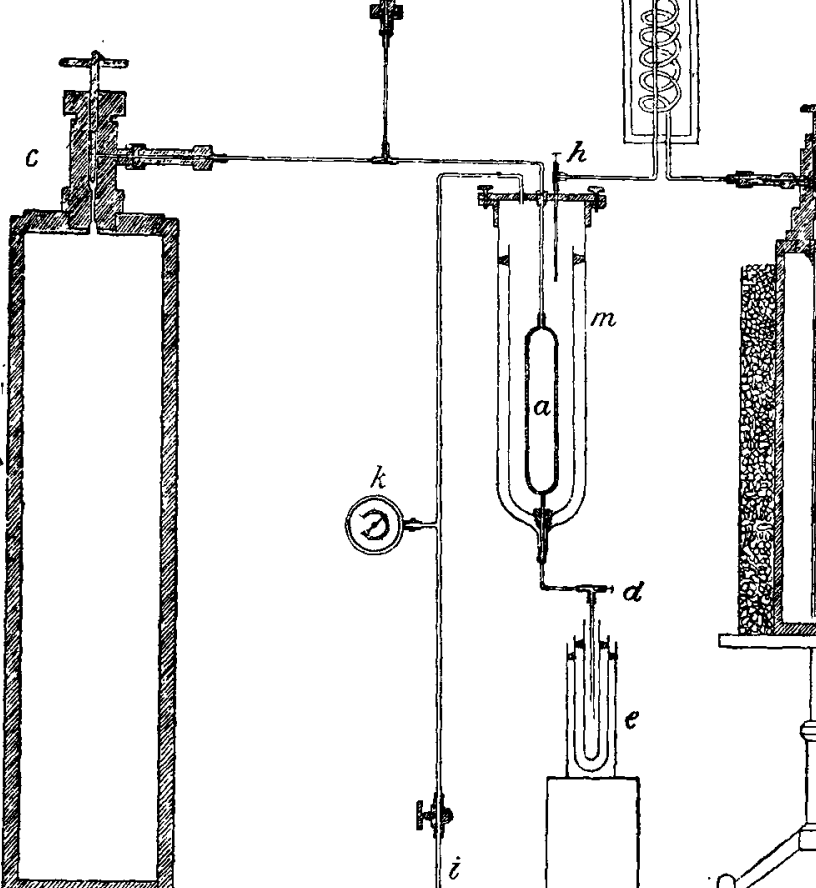

out about 1 litre of gas. When the pressure in the condenser $g$ is lowered to 50 millim. Hg, the vessel $m$ is connected, by turning the cock $i$, with a large vacuum-pump provided with sliding-valves, and at the same time, by slowly turning the cock $h$, the ethylene, already considerably cooled, is let down into the vessel $m$. The liquid ethylene, on entering the vessel $m$, at first evaporates quickly, and the vapour is forced back into a gasometer by means of the large pump alluded to, and may again be employed as a frigorific agent for a subsequent experiment. Owing to the very great difference between the temperatures of the steel cylinder and the liquid ethylene, the latter does not at first touch the cylinder directly, but is separated from it by a thin layer of vapour, being in 
the spheroidal state : it is only when the cylinder has cooled considerably that the ethylene comes into direct contact with it; a violent boiling of the liquid shows that this has taken place. Henceforward a more abundant stream of ethylene may be poured in until it fills the vessel $m$ above the cylinder $a$; afterwards the cock $h$ is closed, and the smaller pump which is connected with the vessel $m$ by means of the tube $i$ must be kept working without interruption, by which the temperature of the ethylene is continually lowered; and when it has fallen below the critical temperature of the gas contained in the flask $c$ (oxygen or air), the cock of this flask is slowly opened. The gas enters the cooled cylinder $a$ under the pressure indicated by the manometer $b$, and becomes liquid speedily enough, in consequence of which the index of the manometer shows a constant fall; when it becomes stationary, the cylinder $a$ is wholly filled with the liquefied gas. When this has been done, the bottle $c$ is closed, and by slowly opening the cock $d$ the liquefied gas is poured into the glass vessel placed underneath, which is secured from external heat by its triple walls. Whilst the liquid oxygen is being poured from the cylinder $a$, the pressure descends to $20 \mathrm{~atm}$., and remains at this point as long as any liquid oxygen remains in the cylinder: it is only when there is no more that the pressure becomes less than $20 \mathrm{~atm}$. As the liquefied gas comes under the ordinary atmospheric pressure, a considerable part of it resumes the gaseous state, and only half or a third of the liquid remains in the glass vessel after having cooled down to its boilingtemperature. In order to prevent the collected liquid being blown out by the powerful jet, the thin copper tube through which the stream flows is closed beneath, and provided with four lateral openings.

I mentioned above that the temperature of ethylene in the vessel $n$ must be lowered by pumping to less than the critical temperature of the gas we wish to liquefy; but it is not necessary to measure the temperature of the ethylene. It is sufficient to measure its pressure. According to my computations (3), the following relation exists between the pressure and the temperature of the liquefied ethylene:-

$\begin{array}{cc}\text { Pressure. } & \text { Temperature. } \\ \text { millim. Hg. } & -122 \\ 146 & -126 \\ 107 & -1297 \\ 72 & -132 \\ 56 & -139 \\ 31 & -148 \\ 12 & -150.4 \\ 9 \cdot 8 & \end{array}$

02 
The critical temperatures, also according to my reckonings, are : for oxygen $-118^{\circ} .8 \mathrm{C}$.; for air $-140^{\circ} \mathrm{C}$; f for nitrogen, $-146^{\circ} \mathrm{C}$. The pressure of ethylene must accordingly be lowered to $100-40$ millim. in order to liquefy oxygen; to liquefy air, to 20 millim., and to liquefy nitrogen, to 10 millim.

The pressure to which ethylene is subjected in the vessel $m$ is indicated by the metallic vacuometer $k$, for which in more exact experiments a mercury manometer may be substituted. The pressures I have stated above for ethylene are maximum pressures at which it is still possible to bring about the liquefaction of large quantities of the corresponding gases ; but it is generally necessary to take care that the pressure of the liquid ethylene be lowered to the minimum obtainable by the pump serving for the experiment. The nore we lower the temperature of the ethylene, the sooner the cylinder $a$ is filled with the liquefied gas, and the more liquid we obtain by pouring out the liquefied gas under the ordinary pressure. To lower the temperature of a considerable quantity of ethylene to $-146^{\circ}$ or $-150^{\circ} \mathrm{C}$., which temperature is absolutely necessary for the liquefaction of large quantities of air and nitrogen, a large air-pump with rapid and powerful action is required. When in $1890 \mathrm{I}$ used a smaller pump, which drew out two litres of gas at each complete double stroke, I could only liquefy oxygen in the described apparatus ; but when in the following year 1 brought from Burckhard's factory, Basle, an excellent sliding valve-pump, six times larger than the preceding one, and working with great speed and perfection, I was enabled in the same apparatus easily to obtain at once 200 cub. centim. of liquid air. It is true that I never tried to liquefy nitrogen in large quantities, but I believed it unnecessary, taking into account my former experiments with nitrogen (6). I had already examined the properties of liquid and solid nitrogen, and showed that the use of liquid nitrogen as a frigorific agent is of no greater advantage than that of oxygen or air. However, considering that by using both of my pumps the pressure of ethylene in the vessel $m$ is easily lowered to 10 millim. and the temperature to $-150^{\circ} \mathrm{C}$., I can decidedly affirm, that all so-called permanent gases, except hydrogen, may be liquefied in my apparatus. When we want to obtain such a considerable rarefaction of ethylene, the compressing tube of the larger pump must be connected with the exhausting tube of the smaller one, whereby the effect of the larger pump is exceedingly increased.

It need hardly be said that the processes connected with the liquefaction of large quantities of gases, as the liquefaction of ethylene in the cylinder $f$, the charging of the cylinder $c$ 
with oxygen or air, and the working of both the larger and smaller pump, must be accomplished not by hand, but by means of a gas-motor of 1-3 H.P.

The indispensable condition for such experiments to be successful, is the purity of the gases to be liquefied; the liquid carbon dioxide, used as a frigorifie agent, must be free from moisture ; the ethylene, oxygen, and air must be completely dry and free from carbonic acid. A small amount of carbon dioxide in oxygen or air renders these gases turbid and opaque when liquefied : a slight quantity of moisture may freeze and stop up the narrow tubes which join together the component parts of the apparatus, and thus frustrate the experiment, prepared with so much trouble. In order absolutely to purify oxygen and air from water and carbon dioxide, there must be put into the bottle $a$, before it is charged, 1 kilog. of potassium hydroxide in thin sticks, that will in a few days completely absorb the moisture and carbonic acid which may be produced whilst the gas is being forced into the flask, in consequence of the action of the condensed oxygen on the leather piston of the pump.

The quantities of liquid oxygen and air I got by means of the apparatus described were quite sufficient for carrying out my experiments on the liquefaction of hydrogen and the examination of the optical properties of liquid oxygen, which I shall shortly describe. On that account 1 did not think it necessary to increase the dimensions of the apparatus (which, however, it would have been easy to do), the more so because, after having liquefied the first 200 cub. centim. of oxygen or air, the operation may be repeated every 15 minutes, on an equal quantity of gas, as long as the store of liquid ethylene suffices, and the pressure in the bottle $c$ does not fall below $60 \mathrm{~atm} .:$ in this case other cylinders, containing the whole charge of the corresponding gas, should take the places of $c$ and $f$.

I now pass to the description of the experiments I have executed by means of the apparatus described, either by myself or working in conjunction with Prof. Witkowski.

On the Absorption Spectrum and the Colour of Liquefied Oxygen.

[Notice published in German in the Bulletin International de l'Academie de Cracovie, January 1891, and in Wiedemann's Annalen, 1891, vol. xlii. p. 633.]

ln my earlier investigations * I found four absorptionbands in the spectrum of liquid oxygen, corresponding to the

* Wiener Akademie Berichte, xcv. p. 257. 
wave-lengths $628,577,535$, and 480 . Messrs. Liveing and Dewar *, who at a later date examined the absorption spectrum of gaseous oxygen in a long steel tube under a strong pressure, found the same four absorption-bands in the visible part of the spectrum, and, besides them, in the utmost red two others, corresponding to the lines $A$ and $B$ of the solar spectrum, which were also observed by Egoroff and Janssen.

The apparatus I have described enabled me to repent my former experiments and to examine more exactly the absorption spectrum of a thicker layer of liquid oxygen in the utmost red.

The liquid oxygen was poured out of the liquefying apparatus into a thin-walled glass tube, the lower end of which was soldered and closely fixed into three glass vessels one outside of the other, to preserve it from external heat. The column of oxygen was 30 millim. thick and about 50 millim. deep. In this glass tube the oxygen remained at its boiling temperature $\left(-181^{\circ} \cdot 4\right.$ C. $)$ under atmospheric pressure, in sufficient quantity for the experiment, during more than half an hour, though it was strongly heated by a Drummond's lime-light, concentrated on it by means of a collecting-lens : this light was used to produce the absorption spectrum. In examination of the spectrum I used a universal spectroscope of Krüss, with a prism of Rutherford. Besides the four known absorption-bands, the experiment also proved the existence of a fifth band, corresponding to the solar line $A$ : it is somewhat blurred, but can be seen distinctly enough if a red glass is put between the source of light and the slit in the spectroscope. This band appeared feebler than the absorption-bands which correspond to the wave-lengths 628 , 577 , and 480 , but stronger than the absorption-band at 553 . With this relatively slight dispersion, the band $A$ could of course not be decomposed into lines. And this time too I was unable to perceive any absorption corresponding to the solar $B$.

The experiments in 1883 made out liquid oxygen to be a colourless fluid, for but small quantities of it were then obtained. Since then I have several times observed that oxygen, when liquefied in wider tubes about $15 \mathrm{~mm}$. thick, appears of a bluish colour. During my experiments already alluded to, in which for the first time a relatively considerable quantity of liquid oxygen was collected in a glass vessel, its bluish colour appeared quite distinctly. This oxygen was prepared from potassium chlorate and manganese dioxide ; to ascertain that it contains no traces of ozone from which the * Phil. Mag. [5] xxvi. p. 286 (1888.) 
bluish colour might be derived, it was carefully tested for that substance. Paper moistened with potassium iodide and starch, exposed for several hours to the action of the oxygen used, was not coloured at all; and when the oxygen was made to pass through a solution of potassium iodide and starch the result was the same. It remained for several woeks in an iron flask, in contact with solid potassium hydroxide, and was by this means completely purified from carbonic acid, vapour of water, and chlorine. After these experiments, there is no doubt that liquid oxygen, seen in layers of about 30 millim., possesses a distinctly bluish colour. This colour is, moreover, quite in agreement with the absorption spectrum of oxygen. It was rather strange that a colourless liquid-as it was hitherto thought to be-should give such a pronounced absorption spectrum, in which the absorptions in orange, yellow, and red are preponderant; but after the bluish colour of liquefied oxygen was proved, this apparent contradiction no longer exists.

I may conclude with a word or two about the colour of the sky. There exist so many hypotheses on that point, that I scarcely venture to add one more. But the simplest theory, in my opinion, would be to ascribe that colour to the principal component part of our atmosphere, which-at least in a liquid state-is blue.

\section{On the Critical Pressure of Hydrogen.}

[These researches were published in Polish, in the Reports of the Cracow Academy 1891, vol. xxiii. p. $385 ; a$ short German abstract therefrom was printed in the Bullet. Intern. of the same Academy. The following description is taken from the first-named source, and is explained by figs. 2 and 3.$]$

In my former researches, undertaken in 1884 and 1885 , I showed that hydrogen cannot be liquefied even by employing the lowest obtainable temperatures and a high pressure, reaching to $190 \mathrm{~atm}$. ; and that it is only during the sudden expansion from a high pressure that a greater or less trace of liquefaction can for an instant be seen. This depends on the temperature of the frigorific medium, as well as on the initial pressure of expansion. As cooling agents there were employed :- oxygen boiling under atmospheric pressure $(t=$ $\left.-181^{\circ} \cdot 4\right)$ and in vacuo, reaching to 9 millim. $\left(t=-211^{\circ} .5\right)$; also air boiling under atmospheric pressure $\left(t=-191^{\circ} \cdot 4\right)$ and in vacuo at $10^{\circ}$ millim. $\left(t=-220^{\circ}\right)$, as well as nitrogen boiling under atmospheric pressure $\left(t=-194^{\circ} \cdot 4\right)$ and in vacuo at 60 millim. $\left(t=-213^{\circ}\right)$. 
I also showed that nitrogen, boiling in vacuo at 4 millim., gives the lowest possible temperature, reaching $-225^{\circ}$, but that it can be used as a cooling agent only as far as $-213^{\circ}$, for at lower temperatures, under pressures below 60 millim. $\mathrm{Hg}$, it solidifies to a snowy opaque mass, which is a bad conductor of heat. It follows that liquid oxygen and air are the best means to obtain the lowest temperatures, for neither of them solidifies at all, even at the lowest pressures, and neither possesses transparency. I had already used these cooling agents in my former attempts to liquefy hydrogen; I then exhausted all possible means of obtaining the lowest temperatures without obtaining the desired results ; for the temperature of $-220^{\circ}$, i. e., the lowest which can be produced by means of liquefied air, proved to be above the critical temperature of hydrogen.

On repeating my former experiments I had no hope of obtaining a lower temperature by means of any cooling agent, but I hoped that the expansion of hydrogen would be more efficacious, on account of the larger scale on which the experiment was made.

The quantity of the frigorific medium, viz., of liquid air or oxygen, did not exceed 2-3 cub. centim. under atmospheric pressure, and became considerably less by the use of the vacuum; accordingly, the glass tube which contained hydrogen was only 2 millim. in internal diameter. The phenomenon of liquefaction, or rather of sudden ebullition of hydrogen which appeared in the tube during the expansion, lasted only a fraction of a second, and required a relatively sudden but not complete expansion. The hydrogen, cooled by its expansion below its critical temperature, was at once heated in so narrow a tube to the temperature of the surrounding frigorific medium.

In the subjoined diagram (fig. 2) a represents the lower end of the steel cylinder, serving to liquefy oxygen or air ; this cylinder is enclosed in a glass vessel (double, if oxygen be employed; triple, if liquefied air) which serves to receive liquid ethylene. The cylinder $a$ is a component part of the apparatus represented in fig. 1, and is therefore marked with the same letter; but it was increased for these experiments to 200 cub. centim. in capacity. The glass tube $f$ is destined for the liquefaction of hydrogen; the external diameter of this lower and wider part is 11 millim., the internal diameter is 7 millim. Within it I place a short glass tube, with very thin walls 6 millim. in diameter ; it serves to isolate from the warmer walls of the larger tube the hydrogen which is considerably cooled by its expansion. The tube $f$ is placed in a larger glass tube $e$, with thin walls, measuring 30 millim. in 
internal diameter, and serving to receive the liquid oxygen under atmospheric pressure. The tube $e$ is surrounded by two

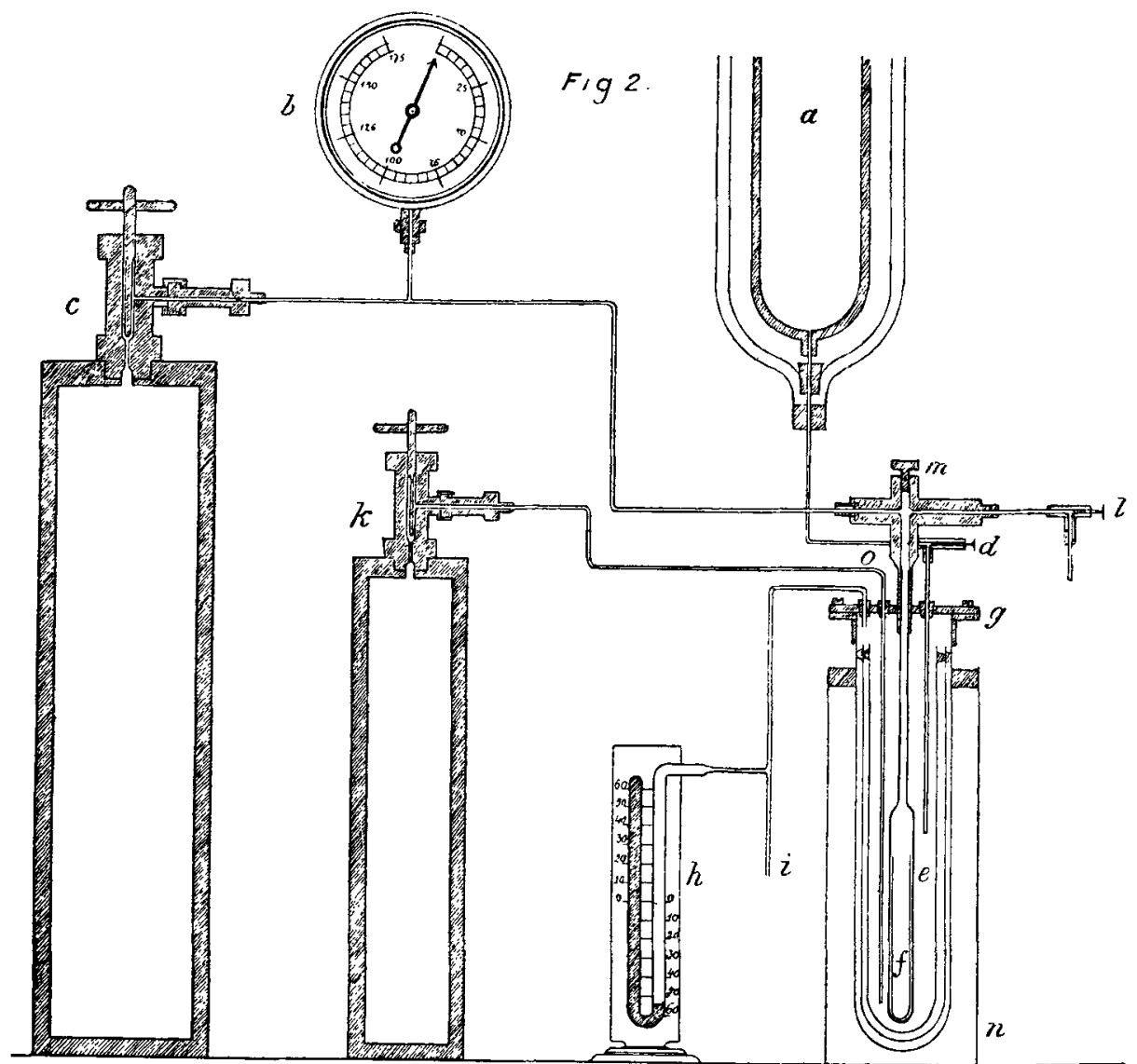

others, of greater and greater diameter, and hermetically closed above with a brass plate $g$. The whole apparatus is hermetically placed in a larger glass cylinder, with calcium chloride at the bottom, serving to dry the enclosed air. The top of the tube $f$ is connected with the manometer $b$ and the iron bottle $c$, containing absolutely pure and dry hydrogen, under a pressure of $150 \mathrm{~atm}$. ; the cock $l$ serves to let the hydrogen out of the tube $f$, thus producing the expansion; through the upper end of the tube $f$, which is closed with the screw $m$, a thermoelectric junction may be introduced, if it be required to measure the temperature of the hydrogen at 
the moment of expansion. I performed the experiment as follows :-

By opening the cock $d \mathrm{I}$ let the liquid oxygen, contained in the steel cylinder $a$, into the vessel $e$; a part of the oxygen. which thus returned into the gaseous state, escaped with violence through the tube $i$; another was cooled down to its boiling-point $\left(-181^{\circ} \cdot 4 \mathrm{C}\right.$.) and collected as a bluish liquid in the tube $e$, to a height of $6-7$ centim., so that the wider part of the tube $f$ was plunged in liquid oxygen. I afterwards closed the cock $d$ and joined the tube $i$ to the pump, by slowly opening a cock, which is not represented in the figure; the mercury manometer $h$ indicated the pressure of the liquid oxygen in the vessel $e$. Liquid oxygen behaves very quietly in the vessel $e$ under atmospheric pressure, boiling quickly bot uniformly on being pumped : if we do not reach very low pressures, the oxygen, after cooling according to the lowered pressure, boils again quietly. But if the pressure falls below 10 millim. (or less), the oxygen boils irregularly, the liquid is thrown up, and shortly disappears. To avoid this I introduced into the vessel $e$ a capillary glass tube $o$, the lower end of which reaches to the very bottom of the vessel $e$, the upper end is connected with the iron cylinder $k$, containing dry hydrogen under a pressure of several atmospheres. During the pumping of the oxygen the cock of the cylinder $k$ is little by little opened, and a slow stream of hydrogen is let through the liquid oxygen ; by this means the liquid oxygen is constantly and easily removed, and it boils quietly, even if the pressure falls to 4 millim.

When the manometer $h$ indicated a pressure of 10-4 millim. I introduced hydrogen into the tube $f$, by slowly opening the cylinder $c$, until the pressure became $140 \mathrm{~atm}$., as indicated by the manometer $b$. When the hydrogen in the tube $f$ has come down to the temperature of the cooling agent, I little by little produced expansion, by opening the screw-cock $l$. The phenomenon of hydrogen ebullition, which was then observed, was much more marked and much longer than during my former investigations in the same direction $(3,4)$. But eren then I could not perceive any meniscus of liquid hydrogen.

I have remarked in these experiments, that with a slow expansion the phenomenon of sudden ebullition always appears under the same pressure, no matter how great the initial pressure may be, provided that value be not too low. So that by expansions made, beginning with the pressures of 80,90 , $100,110,120,130,140 \mathrm{~atm}$., the phenomenon described constantly appeared at $20 \mathrm{~atm}$.; but if the initial pressure was 70, 60 , and $50 \mathrm{~atm}$., the ebullition appeared at a lower and lower 
pressure, viz., approximately at 18, 16, and $14 \mathrm{~atm}$. I repeated the same experiment a good many times, and always obtained the same results. These experiments bring me to the conclusion, that the $20 \mathrm{~atm}$. at which the ebullition of hydrogen always appears represents its critical pressure. If hydrogen, cooled by means of liquid oxygen, boiling in vaeuo, to the temperature $-211^{\circ} \mathrm{C}$., which, we may suppose, is several degrees above the critical temperature of hydrogen, is submitted to a slow expansion from a high pressure, its temperature is lowered to the critical temperature, hitherto unknown. If the initial pressure is high enough-in my experiments it was above $80 \mathrm{~atm}$. - then, by means of a slow expansion, the temperature of hydrogen sinks to its critical value, before its critical pressure is reached, and then liquid hydrogen will appear the moment we lower the pressure to its critical value. But if the initial pressure is too low, a slow expansion cools the hydrogen to the critical temperature only after the critical pressure has been passed: the lower the initial pressure is the greater is the expansion needed to cool the hydrogen below its condensing temperature. We may thus explain the changing pressures, corresponding to the phenomenon of ebullition or instantaneous liquefaction in the case of expansion from an insufficient initial temperature. And if the initial pressure is still lower, the instantaneous liquefaction will not appear at all.

To ascertain the truth of this statement I performed two series of analogous experiments with gases, the critical pressures and temperatures of which are accurately known, viz., with oxygen and ethylene. The critical temperature of oxygen is, according to my former researches, $-118^{\circ} .8 \mathrm{C}$., its critical pressure is $50.8 \mathrm{~atm}$. In the same apparatus which I used for the experiments with hydrogen I cooled oxygen by means of ethylene boiling under atmospheric pressure $\left(-102^{\circ} \cdot 5\right)$, then to a temperature $16 \cdot 3$ degrees below the critical temperature of oxygen, and subjected it to a slow expansion, beginning with different initial pressures, from $40 \mathrm{~atm}$. up to $100 \mathrm{~atm}$. The ebullition of oxygen always appeared at a pressure of about $51 \mathrm{~atm}$., provided the initial pressure was not lower than $80 \mathrm{~atm}$.: at the same time there also appeared a meniscus of liquid oxygen. As the initial pressure became lower and lower, so did the ebullition pressure too.

The critical temperature of etbylene according to Prof. Dewar is $10^{\circ} \cdot 1$, the critical pressure $51 \mathrm{~atm}$.; my own determinations of the same quantities yielded results agreeing well with the above-cited, viz., $10^{\circ} \mathrm{C}$. and $51.7 \mathrm{~atm}$. 
I made similar experiments with ethylene, using the apparatus of Cailletet; one series at a temperature of $17^{\circ} \mathrm{C}$., another at $27^{\circ}$; then at temperatures, which were first $7^{\circ}$, then $17^{\circ}$ higher than the critical temperature of ethylene. During the first series of experiments, the ebullition of ethylene, and at the same time the meniscus, appeared constantly in consequence of a slow expansion at a pressure of about $51 \mathrm{~atm}$., if the initial pressure was $70,80,90,100$, and $110 \mathrm{~atm}$. During the second series of experiments the ebullition appeared at the same pressure, if the initial pressure was 100, 110, 120, and $130 \mathrm{~atm}$. In proportion as the initial pressure was loweredin the first series below $70 \mathrm{~atm}$., in the second below 100 atm.- the ebullition pressure was lowered too. I must, however, mention that in the apparatus of Cailletet, in which I made the experiments with ethylene, the conditions of ebullition of any gas by expansion are much less advantageous than in the apparatus described above.

Hence it follows that the determination of critical pressures by means of expansion is possible, even if the gases have a temperature which is several or many degrees higher than their critical temperature. This dynamical method of determination of critical pressure is really of no advantage if applied to the other gases, for these pressures may be more easily and precisely determined by the vanishing of the meniscus ; but with hydrogen it is the sole possible way to determine not only its critical pressure, but also its critical temperature.

On repeating these experiments in November $1891 \mathrm{I}$ used liquid air, boiling under a pressure of 4-10 millim., as a cooling agent, and obtained the same results, with the only difference that the ebullition of hydrogen on expansion appeared still more distinctly and persisted somewhat longer.

The reason for which it has not been hitherto possible to liquefy hydrogen in a static state, is that there exists no gas having a density between those of hydrogen and of nitrogen, and which might be for instance $7-10(\hat{H}=1)$. Such a gas could be liquefied by means of liquid oxygen or air as cooling agent, and be afterwards used as a frigorific menstruum in the liquefaction of hydrogen.

The subjoined figure 3 , taken from the original, represents $\mathrm{my}$ apparatus for liquefying large quantities of oxygen and air, connected with the apparatus serving to determine the critical pressure of hydrogen. The following brief description will help to understand the figure :-

(a) The steel cylinder, $200 \mathrm{cub}$. centim. in capacity, for the liquefaction of oxygen or air.

(b) The glass vessel with triple walls, serving to receive liquid ethylene under diminished pressure. 
(c) The iron flask, 3 litres in capacity, containing liquid ethylene, under high pressure.

Fig. 3.

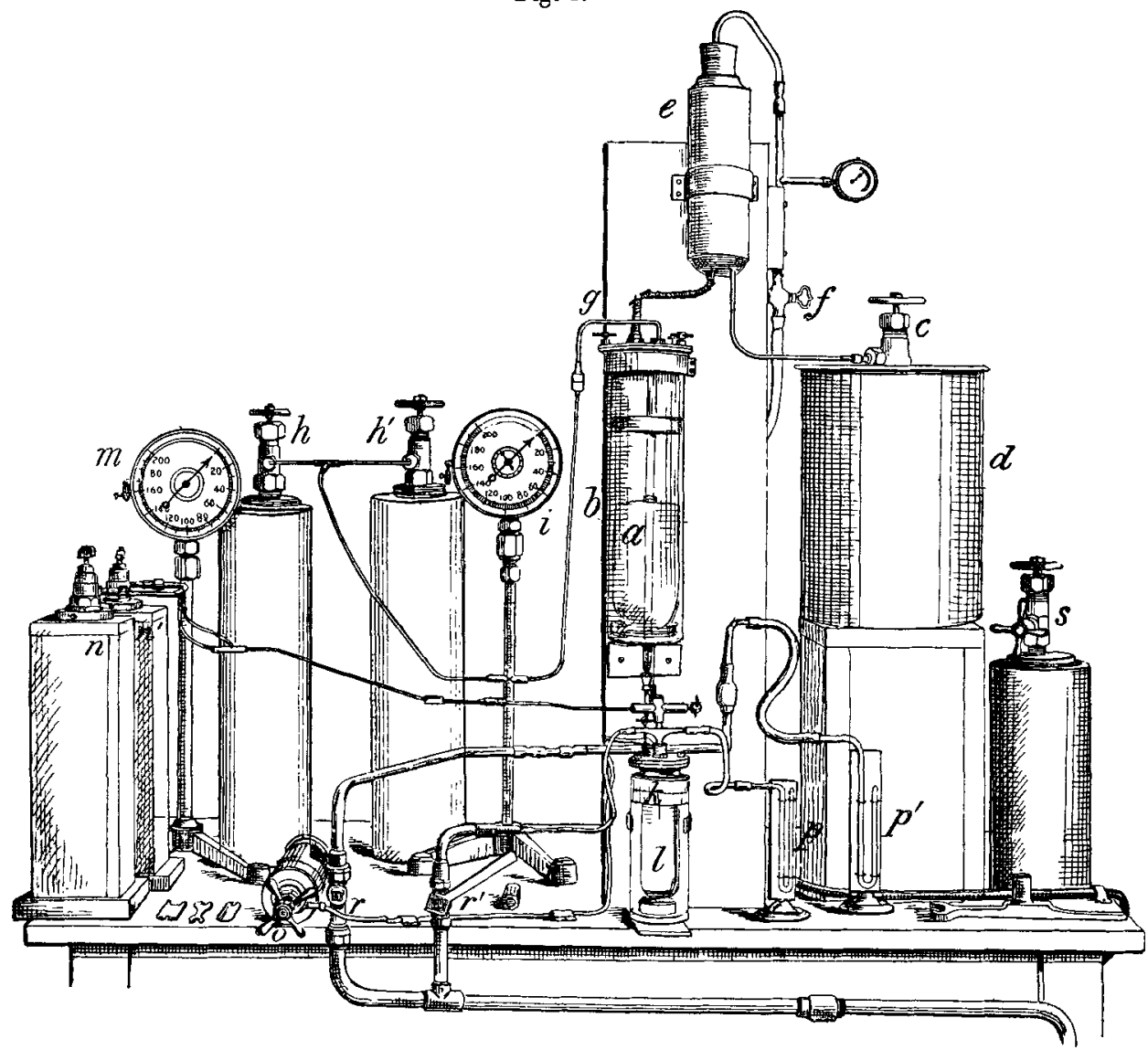

(d) A zinc vessel with ice.

(e) The condenser, for cooling ethylene by means of ether and solid carbon dioxide.

$(f)$ The cock connecting the condenser with the small pump.

(g) The cock serving to let liquid ethylene into the vessel $b$.

$\left(h h^{\prime}\right)$ Iron flasks, 10 litres in capacity, containing oxygen or air under a pressure of $100 \mathrm{~atm}$., connected by means of a tube with the manometer $i$ and the cylinder $a$.

(k) The glass vessel with triple walls, serving to receive liquid oxygen or air under atmospheric pressure. 
(l) The glass tube, plunged in liquid oxygen or air, serving to liquefy hydrogen, connected with the manometer $m$ and iron cylinders $n n^{\prime}$, containing hydrogen under a pressure of $150 \mathrm{~atm}$.

(o) Iron flask containing hydrogen under the pressure of several atmospheres, which passes through the liquid oxygen in the vessel $k$, when its pressure is diminished.

$\left(p p^{\prime}\right)$ Mercury manometers, serving to measure the pressure of ethylene and liquid oxygen, contained in the vessels $b$ and $k$.

$\left(r r^{\prime}\right)$ Cocks serving to connect the vessels $b$ and $k$ with the large pump.

(s) Iron cylinder, containing liquid carbon dioxide.

As my experiments on the liquefaction of hydrogen do not at all confirm those of M. Pictet, made at Geneva in 1879, I requested Dr. Krzyżanowski to examine whether the glaring discreparicies between my experiments and $M$. Pictet's might not be explained by impurities contained in the hydrogen he used. And indeed Dr. Krzyzianowski (24) proved that, if potassium formate be heated with potassium hydroxide, hydrogen cannot be obtained free from moisture, even in the most advantageons case, which occurs when the latter is in excess ; and that if these substances are employed in the proportion given by M. Pictet, that is with potassium formate in excess of what is required by the calculation of molecular weights, we get by heating them a sample of hydrogen containing not only water but also considerable quantities of carbon monoxide and dioxide. Now these substances, interfering with the purity of the hydrogen experimented on by M. Pictet, were doubtless the ground of the extraordinary results M. Pictet described, and which, though glaringly improbable, are cited in nearly all chemical manuals. Perhaps this remark of mine will contribute to a proper appreciation of M. Pictet's experiments respecting the liquefaction and solidification of hydrogen; perbaps it will suggest to the author (who has now established a laboratory in Berlin with the special purpose of obtaining very low temperatures) that he might, with advantage for science, control and rectify the results of the work he performed in 1879 .

\section{On the Optic Properties of Liquid Oxygen.}

[These investigations were made in collaboration with my friend Prof. Witkowski, and were published in the Reports of the Cracow Academy and in the Bulletin International, October 1891 and June 1894.]

As far back as 1887 I discovered a very remarkable and powerful selective absorption of light in the liquefied oxygen. 
It was desirable to obtain some numerical data as regards the absorbing power for the several bands. For this purpose we made use of the spectrophotometer of Glan. The liquid oxygen was contained in the innermost tube, provided with a flat bottom, of the apparatus shown in the annexel figure (fig. 4, taken from the Bulletin International, October 1891).

Fig. 4.

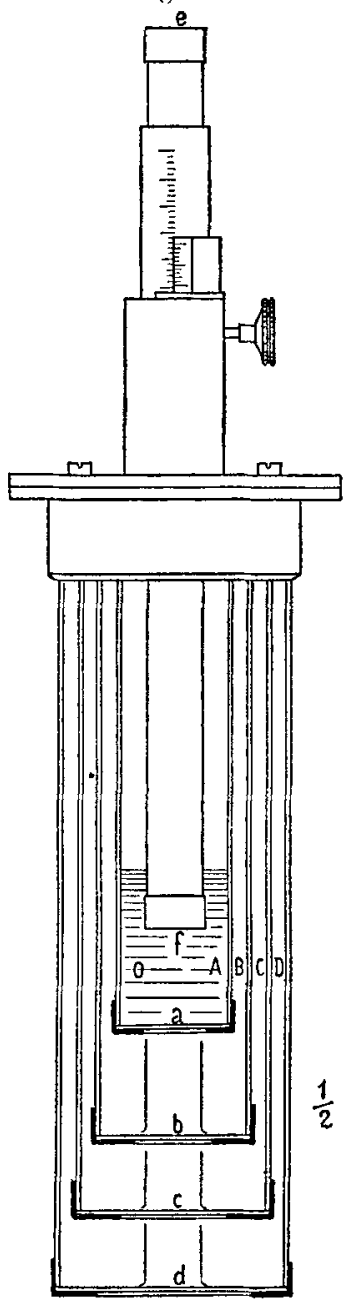

Fig. 5.

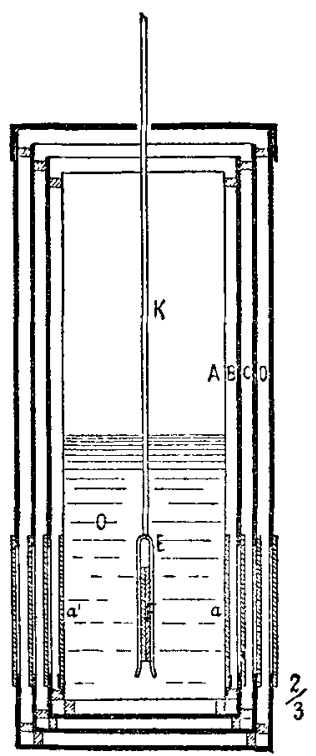

The thickness of the liquid could be varied to a known degree by screwing up and down the tube ef, closed at both ends by plane glass plates, and provided with a millimetre division. 
So far as the accuracy of photometric measurements under such difficult conditions could be relied upon, we found a proportion of light varying between 84 and 89 per cent., transmitted by a layer of oxygen 1 millim. in thickness in the most intense part of the yellow-greenish band $(\lambda=577$ to $\lambda=570)$. The corresponding average number for the red band $(\lambda=630$ to $\lambda=638)$ was 88 per cent.

In the same pamphlet we described a method of determining the coefficient of refraction of liquid oxygen and gave results for sodiun light. The most suitable method for the purpose proved to be that of total reflexion. The liquid is contained in a thin iron parallelepipedon A (see fig. 5), provided with plane glass windows, and protected by several varnished pasteboard boxes of similar form containing some phosphoric anhydride. A double glass plate, composed of two carefully selected plane bits of glass, separated at the corners by small pieces of mica (thickness about 0.006 millim.) and cemented at their obliquely-ground borders by means of fish-glue, is immersed in the oxygen. The double plate is rigidly conected with the axis of a divided circle. A similar arrangement has been employed by Ketteler in some of his investigations on the refraction and dispersion of water (Wiedemann's Annalen, vol. xxxiii.). It is therefore unnecessary to enter into particulars as regards the mode of observation and calculation of results. A first series of observations gave the value 1.2235 of the coefficient for sodium light, in very close agreement with a result found by Messrs. Liveing and Dewar by means of the prism method. Later determinations of the same constant by myself and Prof. Witkowski, made with the view of ascertaining the dispersion of liquid oxygen (Bulletin International, July $1894)$, yielded a rather smaller result $(1 \cdot 2226)$ as a mean of five distinct measurements. At the same time we found $n=1.2213$ for $\lambda=670.5$, and 1.2236 for the wave-length $535 \mu \mu$. Anomalous dispersion, specially sought for, could not be detected.

Besides these researches I have made (partly by myself, partly in collaboration with Prof. Witkowski) certain bitherto unpublished experiments concerning the intensity of chemical energy at low temperatures; I mention them here to complete the list of my investigations. They refer chiefly to two substances, viz. liquid ethylene and oxygen, under the influence of agents which coinbine with these substances at the usual or at a higher temperature. Ethylene, boiling under atmospheric pressure $\left(-102^{\circ} \cdot 5 \mathrm{C}\right.$.) was submitted to the 
action of chlorine and bromine. The action was feeble, but in both cases $\mathrm{I}$ obtained products of combination $\left(\mathrm{C}_{2} \mathrm{H}_{4} \mathrm{Cl}_{2}\right.$ and $\left.\mathrm{C}_{2} \mathrm{H}_{4} \mathrm{Br}_{2}\right)$ in considerable quantity.

The possibility of preparing relatively large quantities of liquid oxygen in open vessels at atmospheric pressure gave us an opportunity to examine the chemical properties of this interesting substance more closely. We ascertained first the exceedingly feeble chemical affinity of liquid oxygen. A piece of metallic sodium in contact with it showed no change in its metallic brilliancy; a hardening of the substance, in consequence of its very low temperature, being apparently the only effect produced. This might have been anticipated, considering that every trace of moisture had been frozen away. Potassium acted similarly to sodium.

But when the reaction of oxidation with light and heat phenomena had already begun, the low temperature $\left(-181^{\circ} 4\right)$ is not able to cool the burning substance to such a degree as to interrupt the reaction. For instance, a piece of ignited wood immersed in liquid oxygen takes fire just as in gaseous oxygen; a steel spring burns and spreads sparks of burning iron, which in this experiment barst the glass vessel of oxygen, and the liquid oxygen was consequently spilt on the table, giving thus the interesting sight of liquid drops rolling and jumping about in a perfectly spheroidal state.

In this connexion, as I had (in 1891) large quantities of liquid oxygen, my friend Prof. Kreutz performed a series of experiments on the behaviour of coloured substances at very low temperatures, and showed that many of them $\left(\mathrm{HgS}, \mathrm{HgI}_{2}\right.$, I, \&c.) become much brighter at $-181^{\circ} 4$.

From this summary of researches, as well as of dates, it follows that the first apparatus serving to produce large quantities of the liquefied so-called permanent gases, with the solitary exception of hydrogen, was constructed by me. This apparatus can be enlarged at will by increasing its parts, but without changing anything in its construction, so that it might be used to obtain liquefied gases in factorie; should they at any time prove of practical utility. By ueans of this apparatus I obtained as large quantities of liquid gases as I wanted; and they were used for the first time on a large scale as cooling agents (for instance, in my attempts to liquefy hydrogen), or as an object of scientific researches (the absorption spectrum of liquetied oxygen, its coefficient of refraction, \&c.)

The experiments of Prof. Dewar are merely the repetition Phil. Mag. S. 5. Vol. 39. No. 237. Feb. 1895. 


\begin{tabular}{|c|c|}
\hline 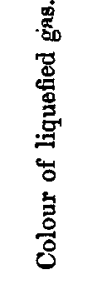 & 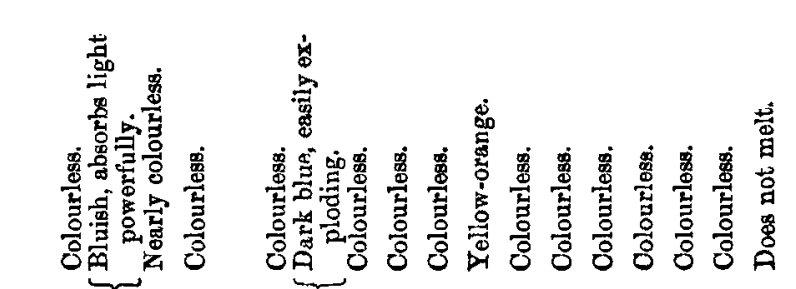 \\
\hline 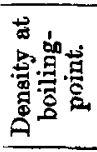 & 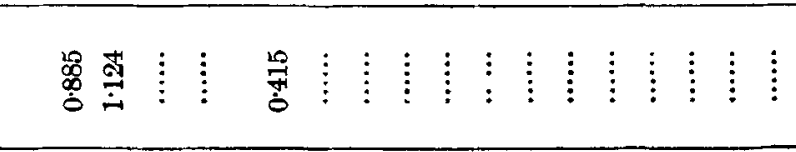 \\
\hline & 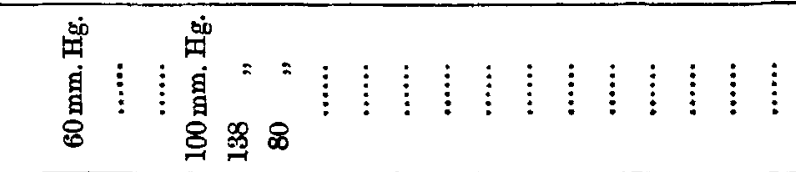 \\
\hline 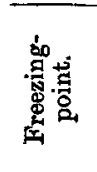 & 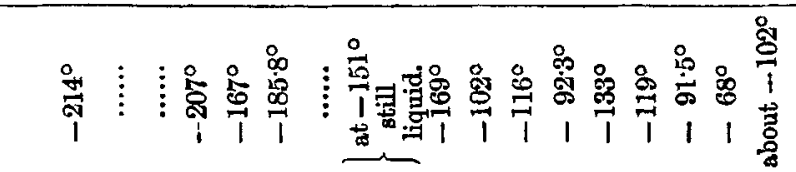 \\
\hline 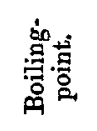 & 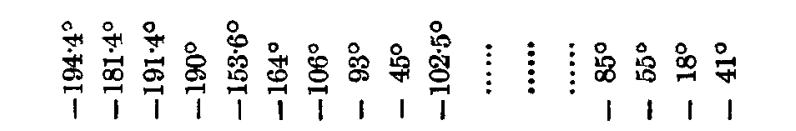 \\
\hline 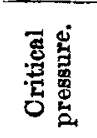 & 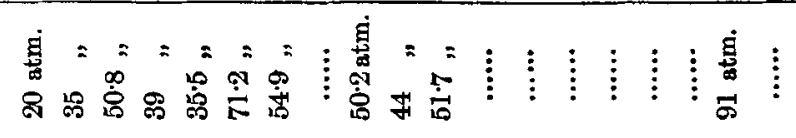 \\
\hline 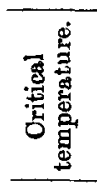 & 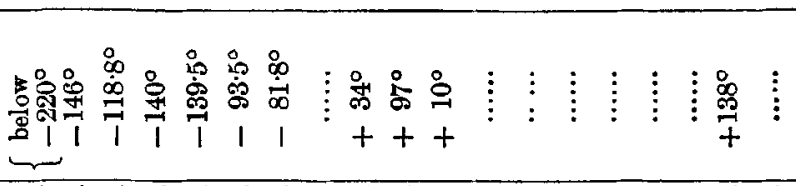 \\
\hline 离 & 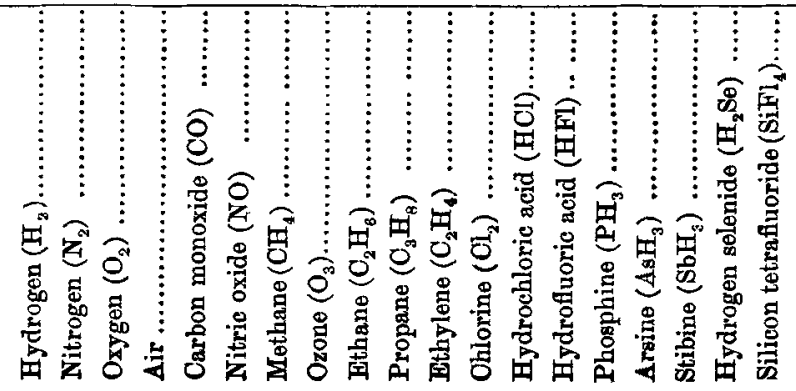 \\
\hline
\end{tabular}


and confirmation of these researches, most of which were putlished several years before his corresponding investigations. His work is really original only as to the magnetic properties of liquid oxygen : that which is not borrowed from my researches is a development of ideas struck out by anotheras, for instance, the experiments on electrical resistance at low temperatures, which were begun by Clausius, continued by Cailletet and Bouty, and bronght ten years ago by my former fellow-worker, the late Prof. Wróblewski ${ }^{*}$, to the temperature of the freezing-point of nitrogen, then several degrees below the temperature attained in the experiments of Messrs. Dewar and Fleming, who, it is true, extended their examination to various metals, alloys, and non-metals. But the execution of these labours meets with no difficulty; for the method of getting large quantities of liquefied gases is now generally known.

In the table opposite (p. 210) I have set down the most important numbers, obtained as stated in my former experiments, concerning the liquefaction and solidification of gases.

\section{List of my Researches, of which I have specified the most important Results in the foregoing Summary.}

All my researches were at first published in the Polish language, in the publications of the Cracow Academy of Sciences; I afterwards published an excerpt of each of them in French and German. The present list contains only French and German papers, as being accessible to students of every nationality. The numbers enclosed in brackets in the preceding summary have reference to the ordinal numbers of the following list.

1. K. OLszewski. Essais de liquéfaction de l'bydrogène.-Comptes Rendus, vol. xeviii. p. 365 (1884).

2. - - Nouveaux essais de liquéfaction de l'hydrogène, soliditication et pression critique de l'azote.-C. $R$. vol. xcriii. p. 913.

3. - Température et pression critique de l'azote. Température d'ébullition de l'azote et de l'éthylène sous de faibles pressions.-O. R. vol. xcix. p. 133 (1884).

4. _- Température et pression critique de l'air. Relation entre la température de l'air et la pression de l'évaporation.C. $R$. vol. xcix. p. 184 (1884).

5. - Belation entre les températures et les pressions du protoxyde de carbone liquide.-C. $R$. vol. xcix. p. 706 (1884).

* Cumptes Rendus, ci. p. 161. 
6. K. Olszewski. Température de solidification de l'azote et du protoxyde de carbone; relation entre température et la pression de l'oxygène liquide.-C. $R$. vol. c. p. 350 (1885).

․ - L. Liquéfaction et solidification du formène et du deutoxyde d'azote.-C. $\lambda$. vol. c. p. $94 \hat{0}$ (1885).

๖. - - Sur la production des plus basses températures. $-C . R$. vol. ci. p. 238 (1885).

9. —- Bestimmung der Diebte und des Ausdehnungscoëfficienten des fluissigen Sauerstoffs.-Anzeiger der Akad. der Wissensch. in Wien, 1884, nr. ix.

10. - - Bestimmung der Erstarrungstemperatur einiger Gase und Fliissigkeiten.-Monctshefte für Chemie, Akad. d. Wissenseh. in Wien, vol. v. p. 127 (1884).

11. - - Erstarrung des Fluorwasserstoffs und des Phosphorwasserstoffs, Verflüssigung und Erstarrung des Antimonwasserstoffs.-Sitzungsberichte d. Akad. in Wien, vol. xciv. p. $209(1886)$.

12. — - Bestimmung des Siedepunktes des Ozons und der Erstarrungstemperatur des Aethylens.-Ibidem, vol. xcv. p. 253 (1887). Also Wiedemann's Annalen, vol. xxxiii. p. $570(1888)$.

13. - - Ueber das Absorbtionsspectrum des fiüssigen Sauerstoffs und der verflüssigten Luft.-Ibidem, vol xcr.p. 257 (1887). Also Wiedemann's Annalen, vol. xxxiii. p. 570 (1887).

14. s. W Róblewski and K. Olszewski. Ueber die Verflüssigung des Sauerstoffs, Stickstoffs und Koblenoxyds. - Wiedemann's Annalen, vol. xx. p. 243 (1883).

15. K. OLszewskr. Ueber die Dichte des flüssigen Methans sowie des verflüssigten Sauerstoffs und Stickstoffs.-Ibidem, vol. $\mathrm{xxxi}$ p. 58 (1887).

16. - - Ueber das Absorbtionsspectrum und iiber die Farbe des flüssigen Sauerstoffs._Ibütem, vol. xlii. p. 663 (1891).

17. - . Sur l'éthane et propane liquides._Bulletin International de l'Académie des Sciences de Cracovie, Jannary 1889, I.

18. — - Appareil pour liquéfier et solidifier les gaz appellés permauents et pour étudier leur spectre d'absorbtion.Ibidem, January 1889.

19. — Sur les propriétés physiques de l'acide selénhydrique soumis à une basse température et à la pression.-Ibidem, February 1890.

20. - _. Transvasement de l'oxygène liquide.-Ibidem, June 1890 .

21. - Ueber den kritischen Druck des Wasserstoffs.Ibiden, May 1891.

22. Olszewsini and A. Witkowski. Propriétés optiques de loxygène liquide.-Ibidem, October 1891.

23. - - Sur la dispersion de la lumière dans l'oxygène liquide.-Ibidem, July 1894.

24. K KRzYŻanowskl. Sur la liquéfaction et la solidification de l'hydrogène dans les experiences de M. Pictet.-1bidem, January 1889. 